\title{
URUGUAY 2019. Fin DEL CICLO PROGRESISTA Y REESTRUCTURA DEL SISTEMA DE PARTIDOS
}

\author{
Uruguay 2019: Party System Restructuring and the End of the \\ Progressive Cycle
}

\section{LIHUEN NOCETTO}

Pontificia Universidad Católica de Chile

\author{
RAFAEL PIÑEIRO \\ Universidad Católica del Uruguay
}

\section{FERNANDO ROSENBLATT}

Universidad Diego Portales, Chile

\begin{abstract}
RESUMEN
El año 2019 supuso cambios en el sistema político uruguayo. El Frente Amplio (FA), partido de centro izquierda en el gobierno desde 2005, perdió la presidencia a manos de una coalición de partidos de centro-derecha, la Coalición Multicolor liderada por Luis Lacalle Pou del Partido Nacional (PN). Este artículo ilustra la importancia de las variables económicas en las elecciones presidenciales en el Uruguay. La alternancia de partidos en el gobierno estuvo acompañada de cambios en el bloque de centro derecha del sistema de partidos. Un nuevo partido de derecha de creación meteórica, Cabildo Abierto (CA), logró obtener el 10\% de los votos bajo el liderazgo del excomandante del Ejército. De esta forma se convirtió en un actor relevante para la nueva coalición de gobierno, en tanto permite las mayorías parlamentarias.
\end{abstract}

Palabras clave: elecciones, Uruguay, sistema de partidos.

\begin{abstract}
The Uruguayan political system underwent major changes during 2019. The Frente Amplio (Broad Front, FA), a center-left party that had been in office since 2005, lost the national elections against a coalition of center-right parties. This article illustrates the importance of economic variables in presidential elections in Uruguay. The latter coalition was named Coalición Multicolor (Multicolor Coalition) and was led by Luis Lacalle Pou from the Partido Nacional (Partido Nacional, PN). The 2019 national election results yielded not only a government turnover but also a restructuring of the parties on the political right. A new rightist party, Cabildo Abierto (CA), had a meteoric rise. Led by a former Army Commander-in-Chief, CA managed to win 10\% of the votes and has become a key actor in the government coalition.
\end{abstract}

Keywords: elections, Uruguay, party system. 


\section{INTRODUCCIÓN}

La institucionalización de los sistemas de partidos puede ser entendida de diversas formas. Algunos sostienen que la institucionalización es la ausencia de volatilidad (Mainwaring y Scully 1995; Mainwaring 2018) otros la identifican con una forma de cambio paulatino (Buquet 2016). También se asocia la institucionalización con los niveles de éxito de los partidos desafiantes (López-Cariboni 2005) o más en general como la capacidad de adaptación vía incorporación de sectores sociales e intereses emergentes (Piñeiro Rodríguez y Rosenblatt 2020). Sea cual sea la forma de entender, conceptualizar o medir los niveles de institucionalización de los sistemas de partidos, el sistema de partidos uruguayo se cataloga como institucionalizado. Es decir, es un sistema estable que cuando cambia, para adaptarse a cambios en el entorno, lo hace de manera paulatina.

Los años de elecciones presidenciales son hitos en la evolución de los sistemas de partidos que indican cambios y continuidades que responden a factores de corto plazo y de largo plazo que caracterizan a esos sistemas. Las elecciones uruguayas de 2019 no son una excepción en este sentido. Reflejan factores de largo plazo que marcan pautas de continuidad y de corto plazo que señalan cambios enmarcados o contenidos dentro de las pautas de evolución de largo plazo. De esta forma, el cambio de partidos en el gobierno respondió a factores de corto plazo o coyunturales que se reflejaron en los niveles de evaluación de la gestión del Frente Amplio (FA) -en el gobierno desde 2005- y en evaluaciones sociotrópicas negativas sobre la economía. Sin embargo, estos factores no modificaron las pautas de estabilidad del sistema y su configuración programática (Kitschelt et al 2010; Luna 2014). Los resultados electorales no supusieron cambios radicales en la composición y caudal electoral y parlamentario de los principales partidos. Al mismo tiempo, la competencia se siguió desarrollando en una lógica de bloques, uno de centro-derecha integrado por el Partido Nacional $(\mathrm{PN})$, Partido Colorado PC) y Cabildo Abierto $(\mathrm{CA})^{1}$ y otro de centro-izquierda compuesto por el Frente Amplio (FA). ${ }^{2}$

Dentro de esta lógica de continuidad y cambio paulatino, la novedad fue el surgimiento de CA, un partido nuevo de creación meteórica liderado por el excomandante en jefe del Ejército (Guido Manini Ríos) que obtuvo el $11 \%$ de los votos y once diputados. La mayor fragmentación y el cambio en la composición del bloque de centro derecha abren un margen de incertidumbre respecto

\footnotetext{
A estos tres partidos se suman otros dos partidos marginales, el Partido Independiente (PI) y el Partido de la Gente (PG), que en esta última elección obtuvieron un diputado cada uno, de los 99 que integran la Cámara de Representantes. El Partido Independiente solía ubicarse como un partido de centro izquierda y, como otros partidos de este perfil que no integraron el FA y que existieron en el pasado, se lo solía ubicar hasta la elección anterior en el bloque de centro izquierda junto al FA. Sin embargo, en esta elección el PI adoptó una posición de oposición frontal al FA y sus posiciones se acercaron a las del bloque de centro derecha, junto a los partidos con los que luego formaría una alianza electoral para la segunda vuelta.

2 Adicionalmente hay otros dos partidos marginales que no se pueden ubicar en la lógica de bloques. Uno es Unidad Popular (UP) que se ubica a la izquierda del FA que en esta elección perdió su único diputado y otro, el Partido Ecologísta Radical Intransigente (PERI), que obtuvo un diputado.
} 
a las dinámicas futuras de la competencia política en Uruguay. CA jugó como un actor del bloque de centro-derecha en la campaña electoral. Esta actitud fue confirmada con su participación en la formación del nuevo gobierno de coalición. Sin embargo, CA cultivó un perfil político-programático diferente al del PN y PC con pronunciamientos más conservadores, anti-liberales y más nacionalistas que el de sus actuales socios de coalición. Este perfil lo habilita a desprenderse del bloque de centro-derecha y actuar como un partido que compita con este bloque desde posiciones de derecha. A diferencia del PN y PC, que comparten casi todo su electorado, CA tiene un nicho electoral diferente concentrado en sectores populares de posiciones conservadoras de Montevideo y el interior del país. ${ }^{3}$ Este nuevo partido puede entenderse como una manifestación local del surgimiento reciente de nuevas derechas de corte conservador y autoritario asociadas al proceso de cultural backlash (Norris y Inglehart 2019).

La mayor fragmentación del sistema de partidos uruguayos y el surgimiento de un partido de derecha no supone necesariamente un cambio en la estructura de competencia de bloques. Sin embargo, si el surgimiento de CA y su desarrollo político produce una ruptura del bloque de centro-derecha en dos bloques diferenciados, PC y PN más al centro y CA más a la derecha, esto alteraría la dinámica del sistema de partidos en Uruguay. De ocurrir, estas elecciones marcarían el comienzo de un cambio que llevaría al sistema, de un pluralismo moderado con competencia centrípeta a un pluralismo polarizado con competencia centrífuga (Linz 1978; Sartori 1976).

\section{LAS CONDICIONES ECONÓMICAS Y POLÍTICAS DEL CAMBIO DE GOBIERNO}

Hasta antes de la llegada al gobierno del FA en 2005, las evaluaciones que los uruguayos y las uruguayas hacían de la economía no se relacionaban con el desempeño económico del país. Según Luna (2002) esto obedecía a una especie de pesimismo estructural. Este pesimismo suponía que aunque el país creciera, tuviera controlada la inflación o el desempleo, variables usualmente asociadas a los resultados electorales (Erikson, MacKuen y Stimson 2002), la ciudadanía expresaría evaluaciones pesimistas de la economía. La evolución de los resultados electorales en Uruguay no se podía relacionar con el desempeño económico de los partidos en el gobierno. Los partidos del bloque tradicional que estuvieron en el gobierno entre 1985 y 2005 siempre perdieron votos como bloque en detrimento del FA, no importando el desempeño económico del país.

Parte de este perfil diferente al del PC y PN queda reflejado en las posiciones que sostiene el líder de CA en la entrevista en Semanario Voces. 2020, 29 de febrero. “Guido Manini Ríos, senador: Nazis, fascistas, partido militar, un engendro del Pepe. En un año fuimos de todo." Recuperado el 24 de marzo de 2020 de http:// semanariovoces.com/guido-manini-rios-senador-nazis-fascistas-partido-militar-un-engendro-del-pepe-en-un-ano-fuimos-de-todo/. 
Una vez que el FA llegó al gobierno en 2005, dejaron de operar las tendencias electorales de cambio de largo plazo que hacían que el bloque de centro izquierda ganara votos de elección a elección y el de centroderecha los perdiera. Según Buquet y Piñeiro (2014) esta estabilización obedeció a que esa elección supuso la consolidación de un nuevo equilibrio del sistema que había comenzado a producirse en 1971 con la irrupción del FA. ${ }^{4} \mathrm{Al}$ analizar las elecciones de 2014, Buquet y Piñeiro (2015) ponen de manifiesto que en este nuevo equilibrio los resultados electorales en Uruguay tienden a explicarse, como suele ocurrir en las democracias consolidadas y estables, por la evaluación de la gestión del partido en el gobierno, las evaluaciones sociotrópicas de la economía y la popularidad de los candidatos.

\section{La evolución de la economía y de las percepciones sociotrópicas}

La economía uruguaya mostró en el año electoral bajo dinamismo, tendencia que se registra desde 2015 como se observa en el gráfico 1 (Bogliaccini y Queirolo 2017; Carneiro y Traversa 2018; Townsend-Bell 2019). A pesar de los anuncios de una nueva mega inversión extranjera en una planta de celulosa ${ }^{5}$, el crecimiento del PIB en 2019 fue de apenas 0.2\% (BCU 2019). Al margen del valor neto de crecimiento, los sectores que ocupan más personas mostraron desempeños negativos. Por ejemplo, en el sector de la construcción, la actividad tuvo una retracción de $2.8 \%$ en 2018 respecto 2017 y de 2 puntos porcentuales en 2019 respecto al año anterior (BCU 2019). El comercio y sectores de servicios como hoteles y restaurantes cayeron 2.1\% en 2019 (BCU 2019). El enlentecimiento del crecimiento económico y la disminución en la actividad de sectores específicos explican el crecimiento de la tasa de desempleo a su nivel más alto desde 2008 (ver gráfico 1).

4 Diversos autores han hipotetizado sobre las explicaciones de esta tendencia de cambio desde 1971 a 2005. Aguiar (2000) y González y Queirolo (2000) adjudicaban este proceso a cambios demográficos, en particular al reemplazo generacional del electorado. Moreira (2004) también refiere a cambios estructurales, pero pone énfasis en la adquisición de pautas culturales modernas. Las explicaciones más centradas en la política asignan estos cambios a la moderación programática del FA y a la reacomodación ideológica del sistema (Buquet y De Armas 2004; Garcé y Yaffé 2005; Yaffé 2005).

5 La inversión en la nueva planta de celulosa será de cerca de 3 mil millones de dólares al finalizar en 2023. Esta cifra incluye aproximadamente 1,5 mil millones que el Estado invierte en obras de infraestructura pública. 
Gráfico 1. Evolución del Desempleo, Variación interanual del PBI e Inflación. 2006-2019

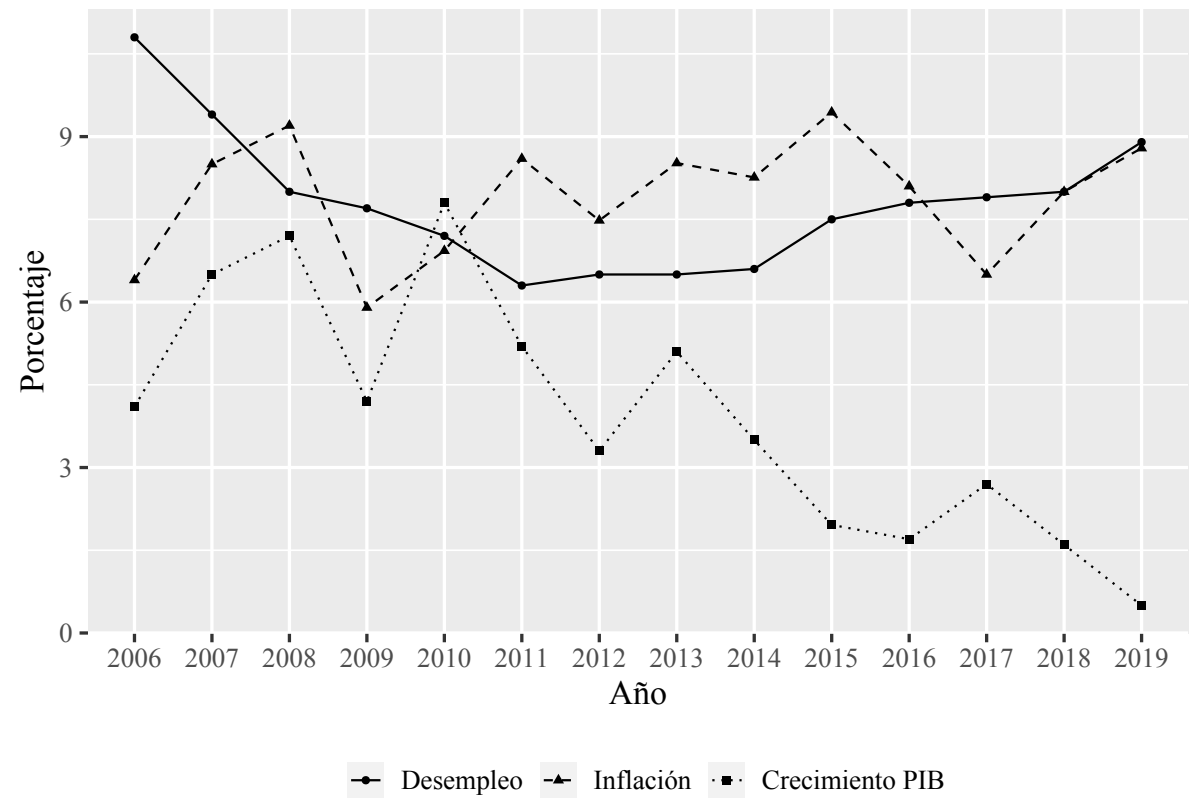

Fuente: elaboración propia a partir de datos del Instituto Nacional de Estadística y Banco Central de Uruguay.

A pesar del enlentecimiento de la economía y el aumento del desempleo la pobreza y la indigencia se mantuvieron en mínimos históricos. Las políticas de regulación del mercado de trabajo y más en general las políticas sociales llevadas adelante por los gobiernos del FA lograron frenar los impactos sociales más negativos del enlentecimiento de la economía. La negociación salarial tripartita por rama de actividad (Consejos de Salarios), la política activa de transferencias monetarias focalizadas, y el gasto público social en general permitió mantener a raya la incidencia del desempeño económico magro sobre la pobreza. El promedio anual de personas bajo la línea de pobreza fue de 8.8\% (INE 2020a). Además, en el año 2019 el salario real se mantuvo constante (INE 2020b). ${ }^{6}$

La política salarial que desde 2005 impulsó el gobierno del FA que supone indexación anual o semestral según rama de actividad en base a negociación tripartita ha generado aumentos ininterrumpidos del salario real desde ese año. 
Gráfico 2. Evolución del porcentaje de personas pobres y extremadamente pobres. 2002-2019

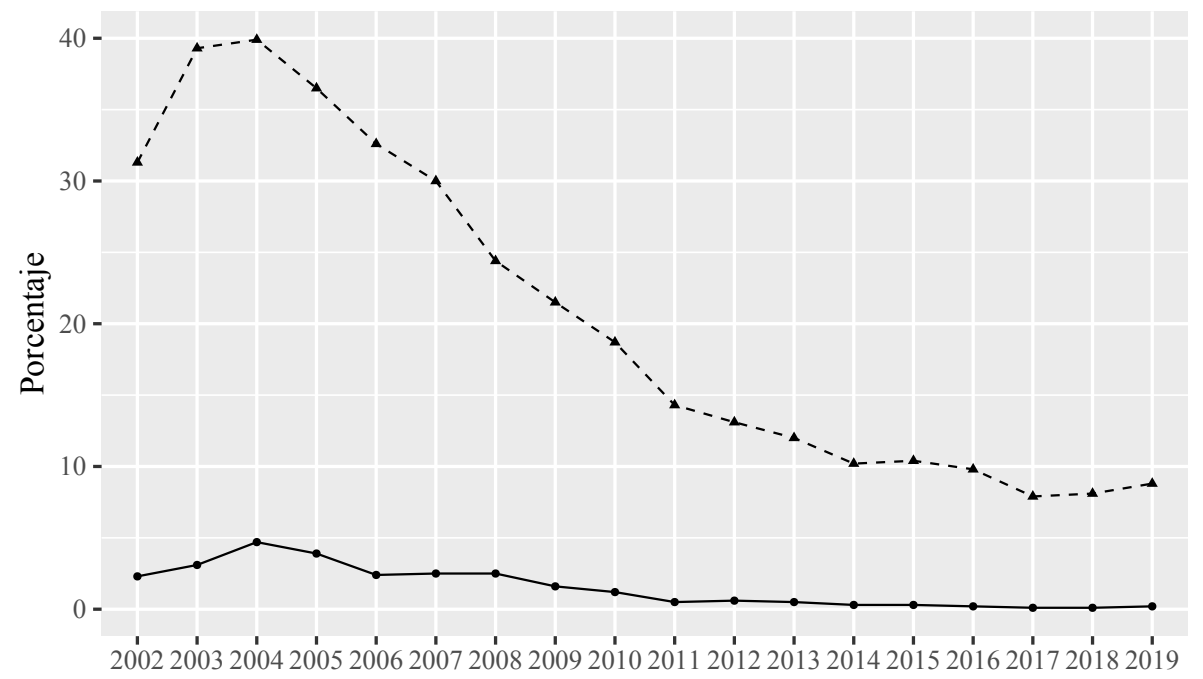

Año

$\rightarrow$ Personas en pobreza extrema -^- Personas pobres

Fuente: elaboración propia a partir de datos del Instituto Nacional de Estadística.

El enlentecimiento económico de los últimos cinco años ha hecho recrudecer los debates en torno al gasto público y la carga tributaria, en especial ha puesto de manifiesto el trade-off entre crecimiento y redistribución (Pérez y Piñeiro 2016). En 2016, el gobierno aumentó la carga tributaria directa para trabajadores con ingresos mayores a USD 1000 (Bogliaccini y Queirolo 2017). Desde este año se intensificó también la discusión sobre la política tarifaria de los servicios públicos. ${ }^{7}$ Las cámaras empresariales y el Movimiento "Un Solo Uruguay" (movimiento de productores rurales) sostuvieron durante todo el quinquenio que las tarifas públicas estaban siendo usadas para financiar el gobierno central (Carneiro y Traversa 2018). Para estos actores, la política tarifaria y la carga tributaria general afectaba directamente la estructura de costos y competitividad del sector. En enero de 2019, el gobierno decretó para las tarifas públicas ${ }^{8}$ un aumento promedio de $6.5 \%$. A pesar de que en términos reales el precio de los servicios públicos disminuyó, los partidos de oposición utilizaron la propuesta biernos suelen transferir los dividendos derivados de las utilidades de estas empresas para cubrir el gasto del sector público.

$8 \quad$ Electricidad (Administración Nacional de Usinas y Transmisiones Eléctricas, UTE), agua (Administración de las Obras Sanitarias del Estado, OSE), combustible (Administración Nacional de Combustibles, Alcohol y Portland, ANCAP), y telefonía (Administración Nacional de Telecomunicaciones, ANTEL). 
de bajar (o no continuar aumentando) las tarifas públicas como una de las principales promesas de su campaña.

El enlentecimiento de la economía, las restricciones para aumentar la recaudación vía nuevos impuestos y la intención del gobierno de mantener los niveles de gasto, lo llevaron a que paulatinamente fuera creciendo el déficit fiscal que en 2019 cerró en un 4.8\% del PIB (ver gráfico 3). En particular, las transferencias del Estado para subsidiar el sistema de seguridad social y pensiones explican casi la mitad del déficit. Dentro de estas transferencias, las que se realizan al servicio de pensiones militares en 2019 representaron casi 1 punto de PIB (Poder Ejecutivo 2018). ${ }^{9}$ Este fue uno de los temas en que hizo énfasis la campaña de la oposición. No obstante, el nivel de deuda neta de Uruguay $(47.3 \%)$ le ha permitido mantener la calificación de la deuda en el grado inversor BBB (low) (Ministerio de Economía y Finanzas 2020).

Gráfico 3. Déficit Fiscal como porcentaje del PIB anual

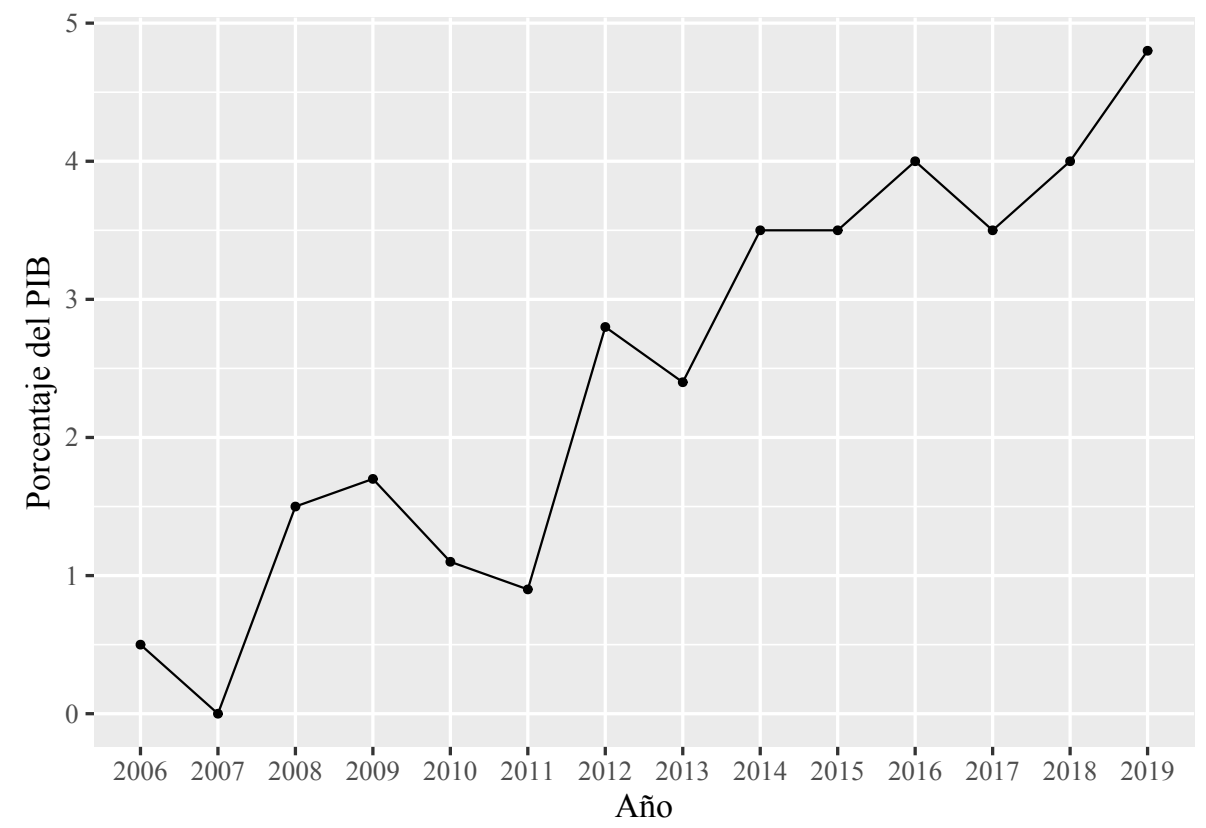

Fuente: elaboración propia a partir de datos del Banco Central del Uruguay.

Uruguay logró evitar la recesión en un contexto internacional adverso para los países emergentes y en particular un contexto regional donde Brasil y Argentina han atravesado crisis muy importantes en los últimos años. Sin embargo, el aumento del desempleo, el enlentecimiento de la economía y el aumento del déficit repre- 
sentan desafíos de mediano plazo que repercutieron en las evaluaciones sociotrópicas de la economía (ver gráfico 4) y fueron materia de debate durante todo el año electoral. El índice de confianza del consumidor ${ }^{10}$ muestra una caída abrupta en el índice en 2015 (primer año de gestión del tercer gobierno del FA). Luego de esa caída, el índice nunca logró recuperar los niveles previos a los de 2015 (ver gráfico 4). Si bien los 51 puntos de octubre de 2019 están por encima del promedio del período marzo 2015 - octubre 2019 (46), son más bajos que los registrados durante el mes de elecciones en octubre de 2009 (64) y octubre de 2014 (62).

Gráfico 4. Evolución del Índice de Confianza del Consumidor. 2007-2019

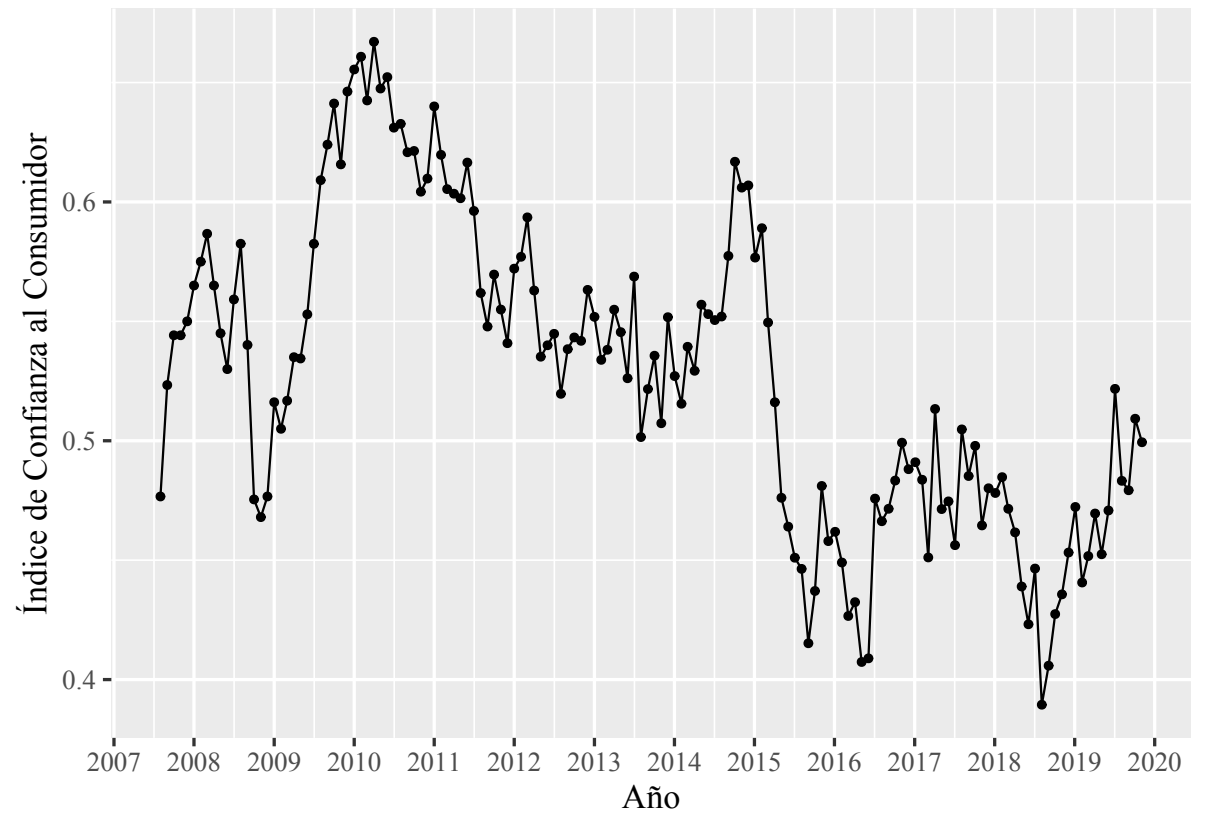

Fuente: elaboración propia en base a datos de Cátedra SURA de Confianza Económica - Universidad Católica del Uruguay y Equipos Consultores

\section{Las evaluaciones sobre la gestión de gobierno}

El año electoral 2019 encontró al gobierno del Frente Amplio (FA) con una de las tasas de aprobación más bajas desde que comenzó a ocupar el Ejecutivo en 2005. Tras catorce años consecutivos de ejercicio del gobierno, todos ellos con mayoría absoluta en ambas cámaras, ${ }^{11}$ el electorado identificó fácilmente

10 El índice de confianza del consumidor se compone de tres dimensiones: 1. la percepción sobre la situación económica personal, 2. la percepción sobre la situación económica del país y 3. La disposición a consumir bienes. Este índice es elaborado por la Universidad Católica del Uruguay y Equipos Mori. Recuperado el 13 de marzo de 2020 de https:/ / ucu.edu.uy/es/icc.

11 Gonzalo Mujica, electo por el FA se separó del partido en 2015 adhiriendo al Partido Nacional. En 2016 renunció a su banca lo que retornó mayorías parlamentarias propias al gobierno (Bogliaccini y Queirolo 2017) 
al gobierno y a su partido (el FA) como responsable por éxitos y fracasos. Al enlentecimiento económico y el deterioro de las evaluaciones sociotrópicas sobre la evolución de la economía, se sumaron evaluaciones negativas respecto a los resultados de política pública principalmente en seguridad ciudadana. En marzo de 2019, a siete meses de la primera vuelta de la elección nacional, el 47 por ciento de la población manifestaba que el principal problema de Uruguay era la seguridad pública, el segundo lugar lo ocupaba el empleo con solo 17 por ciento (Portal Factum 2019).

El deterioro de la seguridad pública impactó en la valoración general de la gestión del FA (ver gráfico 5). Por un lado, el gobierno había prometido en la campaña de 2014 reducir los robos con violencia en un $30 \%$. Sin embargo, estos delitos aumentaron durante el período de gobierno iniciado en 2015, a la vez que se produjo un aumento inusitado de la cantidad de homicidios en 2018. De 8.1 cada cien mil habitantes en 2017, Uruguay pasó a tener 11.8 cada cien mil en 2018. Sin embargo, el gobierno de Tabaré Vázquez decidió mantener tanto la política de seguridad como a los jerarcas responsables. De hecho, el ministro del Interior Eduardo Bonomi ocupó el cargo por diez años consecutivos pasando durante las presidencias de José Mujica y la segunda de Tabaré Vázquez.

Gráfico 5. Evaluación de la Gestión Presidencial. Dos años antes de cada Elección Nacional $(2009,2014,2019)$

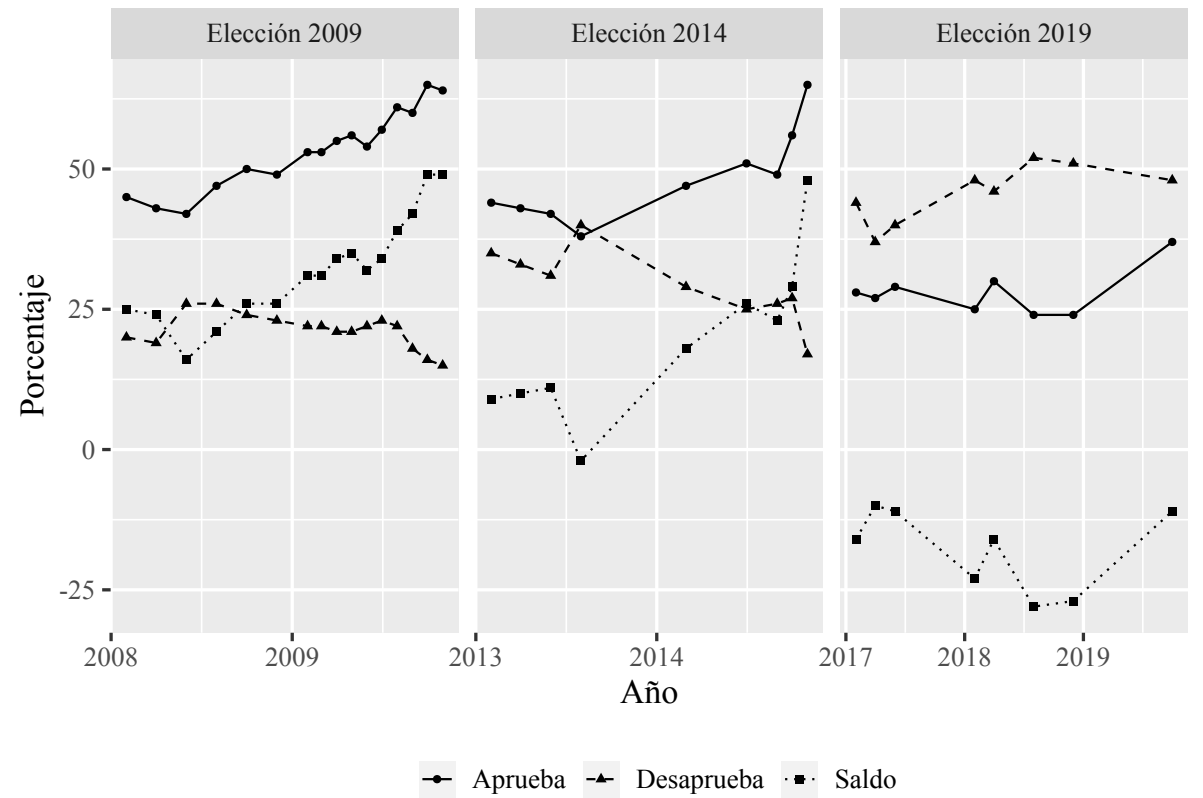

Fuente: elaboración propia en base a datos del Banco de Datos de FCS, UdelaR en base a datos de Equipos Consultores. 
El desempeño negativo de los indicadores de seguridad pública y el aumento de la percepción de violencia es una constante desde fines de los años ochenta (ver gráficos 6 y 7). Sin embargo, la bonanza económica posterior al 2004 facilitó que la seguridad pública se transformara en el principal problema de preocupación de los ciudadanos. En la campaña de 2014 un sector de la oposición había pretendido capitalizar el descontento. La fracción "Vamos Uruguay" del Partido Colorado (PC), liderado por Pedro Bordaberry había impulsado un plebiscito constitucional para bajar la edad de imputabilidad penal de 18 a 16 años, que resultó negativo. ${ }^{12}$

Gráfico 6. Evolución de la Tasa de Homicidios por cada 100,000 habitantes. 2000-2019

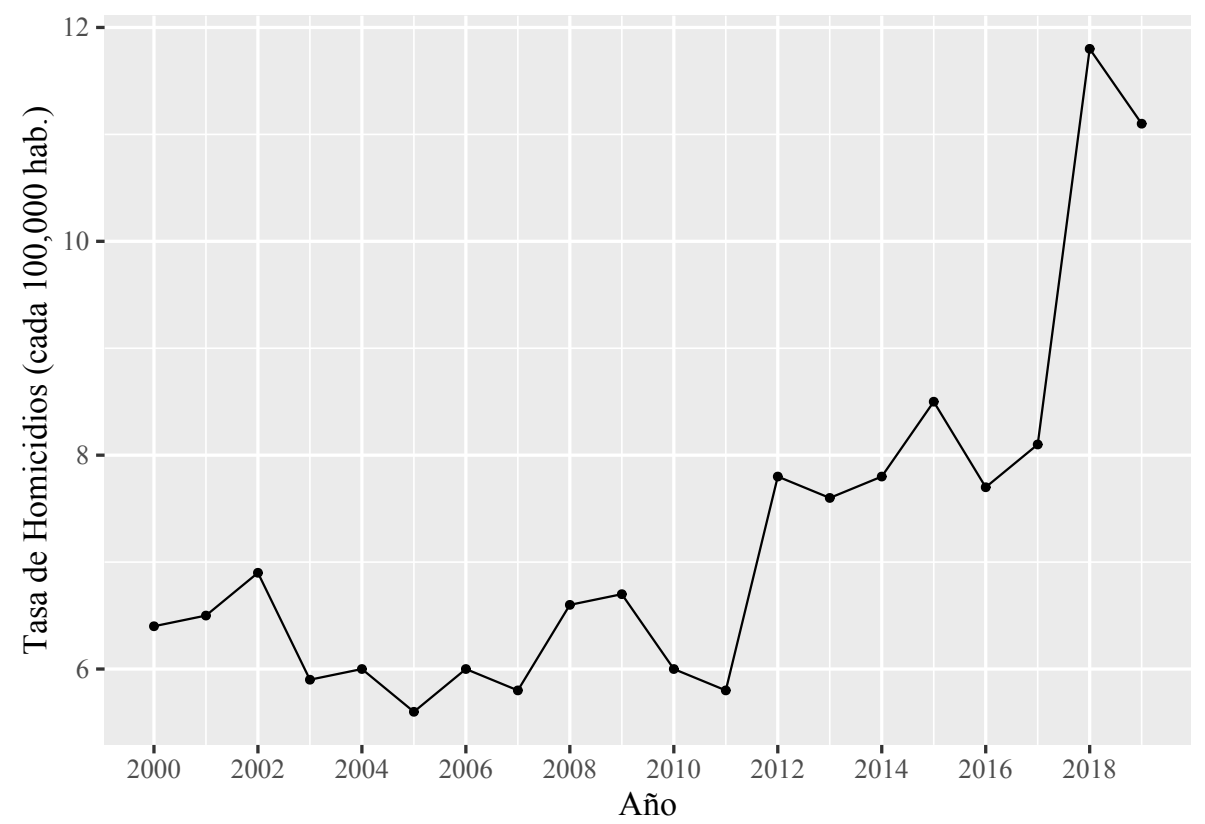

Fuente: elaboración propia en base a datos del Ministerio del Interior.

12 Las adhesiones a favor de la reforma constitucional alcanzaron el 46,8\% de los votantes por lo que no superó la mayoría absoluta necesaria. 
Gráfico 7. Evolución de las denuncias de robos con violencia por cada 100,000 habitantes. 2000-2019

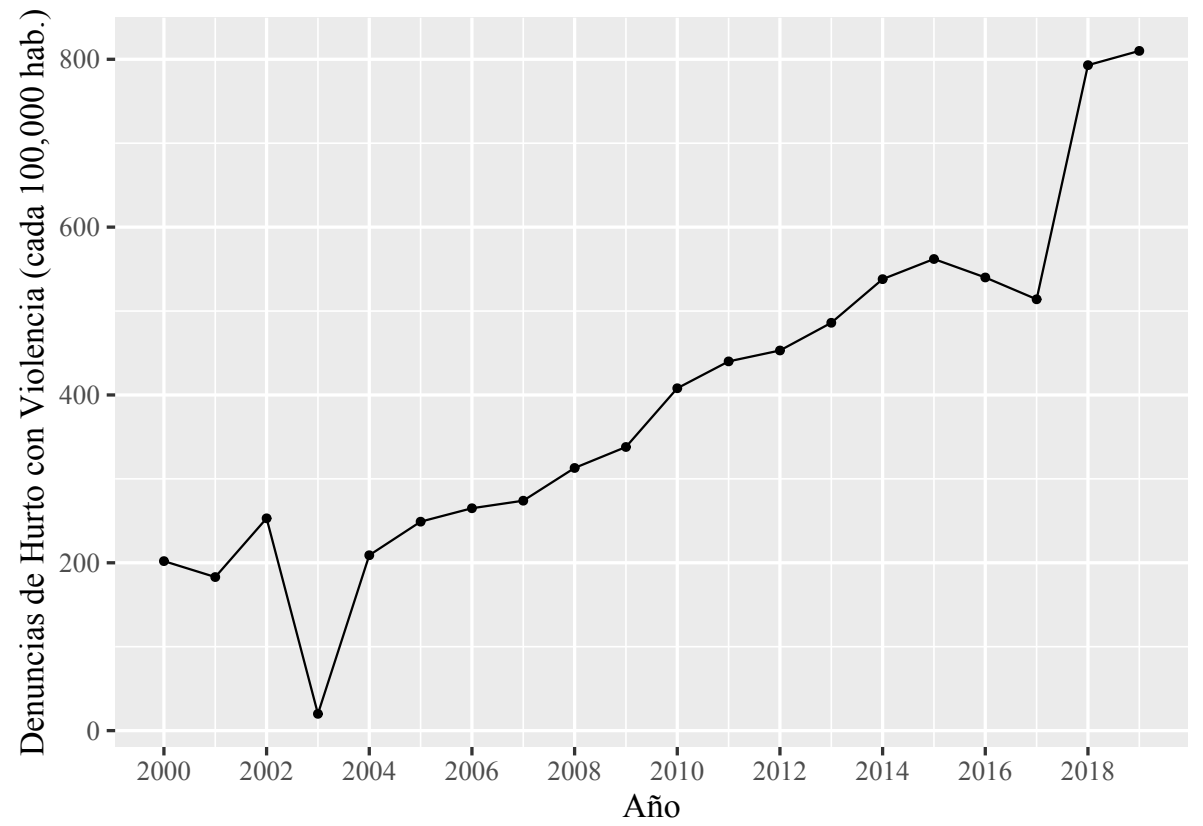

Fuente: elaboración propia en base a datos del Ministerio del Interior.

En 2019, la fracción minoritaria del Partido Nacional (PN), liderada por Jorge Larrañaga, fue la principal impulsora de un nuevo plebiscito constitucional en materia de seguridad. En esta ocasión, los promotores buscaban la creación de una guardia nacional militarizada, la instauración de la cadena perpetua, la supresión de la libertad anticipada para algunos delitos, y la autorización de allanamientos nocturnos. ${ }^{13}$ Este plebiscito tampoco alcanzó la mayoría absoluta de votos $(46.2 \%)$, pero parte de las propuestas fueron incluidas en el programa conjunto de la coalición opositora de cara a la segunda vuelta de la elección presidencial.

A pesar de que la policía tuvo avances sustantivos en sus niveles de profesionalización, organización y equipamiento, los resultados fueron vistos como insuficientes por buena parte de la ciudadanía (BID 2018). Esto repercutió negativamente en las evaluaciones de gestión del gobierno durante todo el período. Asimismo, los problemas que se desataron en la gestión financiera de la petrolera estatal al inicio del período de gobierno y diferentes proyectos de inversión fallidos, lanzados durante el gobierno anterior de José Mujica (2010- 
2015) ${ }_{,}^{14}$ redundaron en que la ciudadanía pusiera en duda las competencias de gestión del FA, lo que impactó negativamente las evaluaciones sobre la gestión del gobierno prácticamente desde su inicio (Pérez y Piñeiro 2016).

Tanto las evaluaciones sociotrópicas sobre la economía, como la evaluación de la gestión en 2019 fueron sensiblemente más negativas que en 2009 y 2014, años en que el FA logró reelegirse en el gobierno (ver gráficos 4 y 5). Como nunca antes en estos últimos quince años el contexto político y económico en que se produjeron las elecciones era más favorable para la oposición que para el gobierno. En este sentido, el margen de incertidumbre sobre el resultado electoral estaba signado por el desempeño de los partidos y la imagen de los candidatos durante la campaña electoral.

\section{ACTIVISMO RESTAURADOR}

Las reformas políticas y sociales del Frente Amplio encontraron este año mayores niveles de activismo contrario a su agenda progresista. Este activismo de carácter restaurador enfrentó tanto la agenda de derechos como algunas reformas económicas. Con relación a la agenda de derechos, a fines de 2018 el oficialismo logró aprobar con voto de todos los partidos en la Cámara de Representante ${ }^{15}$ la "Ley Integral para Personas Trans" (número 19.684). Esta ley reconoce el derecho a la identidad a la vez que establece políticas respecto a acortar las desigualdades económicas y de acceso a servicios enfrentadas por esta población. A pesar del apoyo de diferentes partidos, los diputados de filiación evangélica del Partido Nacional iniciaron una campaña para interponer un recurso de referéndum contra esta ley. En agosto de 2019 y con el apoyo de los movimientos evangélicos, la Iglesia Católica y el partido CA se convocó a una elección pre-referéndum. La iniciativa obtuvo un $10.1 \%$ de los habilitados y no logró alcanzar el umbral del $25 \%$ del padrón electoral necesario para convocar a un referéndum.

Las políticas de inclusión financiera también despertaron reacciones de organizaciones de comerciantes. La Ley de Inclusión Financiera (19.210), promulgada en 2014, establece entre sus principales componentes la obligatoriedad del pago de salarios vía entidades financieras, incluso en sectores tradicionalmente informales como el del servicio doméstico o el trabajo rural. En 2019, distintas gremiales empresariales del interior del país, continuaron el proceso de recolección de firmas para reformar la constitución para desarticular las disposiciones

14 Entre los proyectos que no se concretaron y generaron controversia se pueden destacar: instalación de una explotación de minería de hierro (ARATIRI), puerto de aguas profundas en las costas del departamento de Rocha en el este del país, y una planta regasificadora en Montevideo. En los días previos antes de la veda de publicidad electoral el candidato del PN lanzó en sus redes un spot que mostraba imágenes de estos y otros proyectos de inversión malogrados con el hashtag \#15años y musicalizado con el Danubio Azul. Recuperado el 3 de marzo de 2020 de https:/ / www.youtube.com/watch?v=YLMQNhJJ5V4. El tuit con el que Lacalle Pou divulgó el video en sus redes, fue el más retuiteado de los que realizó el candidato en toda la campaña (Bogliaccini et al. 2019).

15 En el Senado solo votaron a favor legisladores del FA y del Partido Independiente. 
establecidas por la política de inclusión financiera. De acuerdo con los promotores de la iniciativa, los aranceles cobrados por los emisores de tarjetas afectaban la viabilidad de los comercios. Según el gobierno del FA, un retroceso en la inclusión financiera implicaría un aumento de la evasión y de informalidad en el trabajo. La campaña de recolección de firmas estuvo apenas por debajo del umbral requerido del 10\%. Si bien esta iniciativa de reforma no logró el apoyo suficiente, sus postulados fueron tomados por el candidato Luis Lacalle Pou (PN), quién se comprometió a derogarla de llegar al gobierno.

Con una estrategia similar, otros sectores intentaron frenar la instalación de una tercera planta de procesamiento de pasta de celulosa. En julio de 2019, luego de las elecciones primarias, el gobierno anunció la concreción de la inversión de la empresa finlandesa UPM para la instalación de una planta de celulosa. El acuerdo entre el gobierno y la empresa que dio lugar a la inversión fue duramente cuestionado por líderes de oposición, ya que el Estado se comprometió a invertir aproximadamente 1.500 millones de dólares en obras viales (vías férreas) para el transporte de celulosa al puerto de Montevideo. El acuerdo incluyó exenciones fiscales y los derechos de uso de aguas otorgados por el gobierno. Esta inversión requiere la construcción de lo que se denomina "Ferrocarril Central." El trazado de esta obra concentró el rechazo de habitantes de ciudades y pueblos del interior que buscan mediante referéndums locales alterarlo (La Diaria 2020).

Ninguna de las iniciativas populares en contra de estas políticas del gobierno logró tener éxito. Sin embargo, les han permitido a grupos de la sociedad como sectores de comerciantes e iglesias lograr impacto sobre el debate político y en particular incluir sus intereses en los programas de los partidos de la oposición. Del mismo modo que los instrumentos de democracia directa fueron claves para la relación entre actores sociales y el FA (Monestier 2007; Altman 2011; Pérez, Piñeiro y Rosenblatt 2020), estas nuevas iniciativas parecen haber acercado a ciertas bases sociales de centro derecha con los partidos de la oposición.

En síntesis, los sectores sociales y políticos opositores al gobierno lograron desarrollar una estrategia de erosión del capital político del FA a través de la movilización y los mecanismos de democracia directa. Sin embargo, líderes y partidos de oposición no se plegaron coordinadamente a estas iniciativas. La agenda más conservadora está asociada a un sector particular del PN y al recientemente creado CA. Sin embargo, es temprano para evaluar hasta qué punto estos sectores podrán conformar un bloque más o menos cohesionado con las capas medias y liberales que han sido principalmente reactivos a la agenda redistributiva del FA pero que son tradicionalmente seculares.

\section{EL SURGIMIENTO DE UN NUEVO PARTIDO DE DERECHA}

La sorpresa del ciclo electoral fue la aparición de un partido de derecha conservadora: Cabildo Abierto (CA). Se fundó en marzo de 2019, apenas días después 
de que el presidente Tabaré Vázquez destituyera a Manini Ríos de su cargo de comandante en jefe del Ejército. CA se integró con dirigentes y militantes provenientes del PN y del PC además de militares retirados. Este nuevo partido centró su campaña en la reinstauración del orden, tanto en materia de seguridad pública como respecto a la agenda de derechos promovida por los gobiernos del FA (El Observador 2019). El discurso de los principales dirigentes de CA durante la campaña tuvo componentes que se pueden señalar como de cultural o illiberal backlash (Hunter y Power 2019; Norris y Inglehart 2019). Por ejemplo, el líder de CA y otros dirigentes relevantes del partido, sostienen posiciones donde: le asignan a los homosexuales responsabilidad por la baja de la natalidad del país, se manifiestan en contra del matrimonio igualitario, y señalan que se prioriza a los inmigrantes por sobre los uruguayos (Queirolo 2020). Una de las frases utilizadas por la campaña de CA fue "se terminó el recreo", en clara referencia a la necesidad de imponer orden y restaurar valores tradicionales.

Se puede rastrear el surgimiento de CA en las rispideces entre el gobierno del FA y el mando de las Fuerzas Armadas que se hicieron cada vez más evidentes durante 2018 y 2019. A comienzos de 2019 se produjo un conflicto entre el Poder Ejecutivo y los mandos militares que terminó por romper los equilibrios con los que el FA manejó la cuestión militar y de Derechos Humanos desde 2005. En febrero de 2019 un periódico reveló que un militar retirado detenido por delitos de lesa humanidad confesó en 2018 ante un Tribunal de Honor del Ejército las torturas, el asesinato y el intento de desaparición del cuerpo de un detenido en 1972. La nota que divulga esta información agrega que el expediente con la confesión se encontraba en la Presidencia de la República y que nadie, ni el mando civil del Ministerio de Defensa, ni los generales del Tribunal de Honor, habían presentado la denuncia a la Justicia Penal.

El presidente Tabaré Vázquez removió al comandante en jefe del Ejército, Guido Manini Ríos, por no haberlo informado debidamente del contenido de las confesiones. También decidió pasar a retiro a los seis generales que integraron los Tribunales de Honor, por no cumplir con lo establecido por la ley. Sin embargo, tanto los generales como el ministro de Defensa señalaron que el Secretario de Presidencia y hombre de extrema confianza de Vázquez estaba al tanto del asunto. Las versiones cruzadas llevaron a la Fiscalía a abrir una investigación por encubrimiento en la que jerarcas de gobierno y militares fueron indagados. Finalmente, la fiscalía decidió encausar al excomandante en jefe del Ejército Guido Manini Ríos. Este escándalo tuvo consecuencias políticas inmediatas. Visibilizó un enfrentamiento entre el estamento militar y el gobierno del FA y potenció el lanzamiento de Manini Ríos como candidato presidencial.

Entre 2018 y 2019, el gobierno avanzó en la agenda para reducir el presupuesto militar directo e indirecto, en especial el asociado a las jubilaciones y pensiones militares. Por un lado, en octubre de 2018 se aprobó la Ley 19.695 que reformó el régimen corporativo de pensiones militares para reducir las transferencias a 
la Caja Militar (Townsend-Bell 2019). ${ }^{16}$ Por otro lado, en agosto de 2019 se aprobó la Ley 19.775 que reformó la Ley Orgánica Militar y cuyo principal punto de conflicto refirió a la reducción de la cantidad de oficiales. Esta agenda fue considerada como un ataque a las Fuerzas Armadas y, junto a la percepción negativa de los militares sobre la persecución judicial a represores de la última dictadura (1973-1985), facilitó la proyección del ex general Guido Manini Ríos como líder de un nuevo partido político. ${ }^{17}$ Además, el ex general proviene de una familia con trayectoria política en Uruguay. Su abuelo, Pedro Manini Ríos, fue diputado, senador y ministro en el primer cuarto del siglo XX. Lideró la fracción conservadora (Riverismo) del PC que se opuso a la fracción progresista liderada por José Batlle y Ordóñez (Batllismo). Su tío, Carlos Manini Ríos, fue también senador, ministro y embajador durante gobiernos del PC en la segunda mitad del siglo XX.

\section{EL CICLO ELECTORAL}

Uruguay celebra elecciones cada cinco años. Tiene un calendario electoral dividido en tres convocatorias para la elección de autoridades nacionales. El último domingo de junio de 2019 se celebraron las elecciones primarias de los partidos políticos. Es la única elección con voto voluntario y define la candidatura única a presidente de cada partido. Además, se eligen las Convenciones Nacionales de los partidos, que son las encargadas formales de nominar al presidente y vicepresidente. ${ }^{18}$ En la misma elección se eligen las convenciones departamentales que definen los candidatos a intendentes departamentales (gobiernos subnacionales) para la elección departamental de mayo de 2020. El último domingo de octubre se realiza la primera vuelta de la elección presidencial y la elección de senadores y diputados, con voto obligatorio. Si ninguna fórmula presidencial obtiene la mayoría absoluta del total de sufragios emitidos, las dos fórmulas más votadas pasan a la segunda vuelta presidencial el último domingo de noviembre.

\section{Elecciones primarias}

En las elecciones primarias del último domingo de junio de 2019 se materializó la emergencia de nuevos liderazgos dentro de los partidos, especialmente en el FA y en el PC. En el FA esto supuso una renovación generacional. El éxito elec-

16 En 2018, las transferencias de Rentas Generales a la Caja Militar fueron de aproximadamente 500 millones de dólares, lo que equivale a 1\% del PIB (Poder Ejecutivo 2018)

17 Manini Ríos fue sancionado por Vázquez con arresto a rigor por 30 días en setiembre de 2018 por criticar públicamente al gobierno en su política reforma de las pensiones militares, lo que está prohibido a militares en actividad.

18 La costumbre establece que el pre-candidato ganador de las primarias es automáticamente el candidato a presidente. Sin embargo, la ley estipula que cuando un candidato no supera el $40 \%$ con un margen de $10 \%$ sobre el segundo, la Convención se transforma en un Colegio Elector pudiendo elegir a cualquiera de los precandidatos que compitieron. 
toral y la ascendencia partidaria de la tríada compuesta por Tabaré Vázquez, José Mujica y Danilo Astori ${ }^{19}$ había dificultado la renovación en ciclos previos (Rosenblatt 2018). Con estos tres líderes pasando los ochenta años, quienes compitieron por la candidatura presidencial del FA fueron Daniel Martínez (socialista), Carolina Cosse (afín al MPP, sector del expresidente José Mujica), Oscar Andrade (Partido Comunista) y Mario Bergara (con el apoyo de sectores que antes habían apoyado a Danilo Astori).

En el caso del PN el desafío a los liderazgos establecidos fue más sorpresivo. A diferencia de lo que ocurrió en el FA, el desafiante fue un outsider. Luis Lacalle Pou y Jorge Larrañaga representan a las dos principales corrientes históricas del PN. Luis Lacalle Pou proviene del herrerismo, corriente más liberal conservadora, mientras que Jorge Larrañaga representa a sectores del wilsonismo, corriente más moderada y desarrollista. Ambos líderes, se aprontaban a reeditar la interna de 2014. Sin embargo, el liderazgo de Larrañaga fue puesto en cuestión por dos factores. Por un lado, la alianza de intendentes departamentales que desde 2004 respaldó a Larrañaga se quebró y un grupo impulsó al intendente de Maldonado Enrique Antía. Por otro lado, un millonario uruguayo residente en el extranjero apareció en Uruguay a fines de 2018 para afiliarse al PN y postularse a la presidencia. El empresario Juan Sartori es un típico outsider que, sin experiencia ni antecedentes políticos, decidió competir dentro de la primaria del PN.

En el Partido Colorado, Pedro Bordaberry, su líder principal decidió retirarse de la política cuando terminara su período como senador. En este escenario, el expresidente Julio María Sanguinetti (1985-1990, 1995-2000) volvió del retiro político para competir por la candidatura presidencial colorada. Se enfrentó a Ernesto Talvi, un economista cercano a la línea más liberal dentro del PC identificada con el expresidente Jorge Batlle. ${ }^{20}$

La elección dentro del FA fue la menos beligerante de las tres primarias de los partidos mayores. Sin embargo, fue la más competitiva desde 2009, cuando José Mujica compitió contra Danilo Astori. Más allá de esto, los precandidatos y la precandidata lograron desarrollar una campaña que no supuso grandes heridas para el partido. En el caso del PN sucedió lo contrario. Una interna que un año atrás parecía dominada por Luis Lacalle Pou, fue alterada por la irrupción de Juan Sartori. El crecimiento abrupto en la intención de voto del outsider, en base a una campaña agresiva que mezclaba gasto en publicidad con esfuerzos de movilización territorial, llegó a desplazar a Jorge Larrañaga del segundo lugar y a poner en duda el claro triunfo de Lacalle Pou. Este nuevo escenario de competencia crispó la campaña, en particular entre Jorge Larrañaga y Juan Sartori. En el PC, con la decisión de Pedro Bor-

19 Astori fue ministro de Economía y Finanzas durante la primera y la segunda presidencia de Vázquez (20052010 y 2015-2020) y vicepresidente durante la presidencia de José Mujica (2010-2015).

20 Jorge Batlle fue presidente entre 2000 y 2005 y lideró el ala más liberal del Partido Colorado desde el retorno a la democracia. 
daberry de no participar de la competencia, Ernesto Talvi parecía ser el claro ganador. El retorno a la arena política de Julio María Sanguinetti también supuso un cambio respecto a lo esperado e hizo que esta campaña no solo fuera competitiva, sino que también por momentos subiera de tono, enfrentando una visión renovadora del partido con otra más tradicional.

A pesar de la aparición de nuevos candidatos (como en el caso del PN, del PC y del FA), la reaparición de líderes retirados (como en el caso del PC) y la no participación de liderazgos establecidos (como en el caso del PC y del FA), los resultados fueron los que en el año anterior se podían prever. En el PN Lacalle Pou ganó con un margen amplio y consolidó su liderazgo, en el FA Daniel Martínez (ex intendente de Montevideo) logró imponerse sin problemas, y en el PC, Ernesto Talvi se impuso con mayor holgura de lo previsto (ver tabla 1).

Tabla 1. Resultados de la Elección Interna de los Partidos Políticos. ${ }^{21}$

\begin{tabular}{lc}
\hline \multicolumn{1}{c}{ Partido } & Porcentaje \\
\hline FA & $\mathbf{2 3 . 7 \%}$ \\
Daniel Martínez & $42 \%$ \\
Oscar Andrade & $23.1 \%$ \\
Carolina Cosse & $25.5 \%$ \\
Mario Bergara & $9.3 \%$ \\
PN & $\mathbf{4 1 . 6 \%}$ \\
Luis Lacalle Pou & $53.8 \%$ \\
Juan Sartori & $20.7 \%$ \\
Jorge Larrañaga & $17.5 \%$ \\
Enrique Antía & $7.5 \%$ \\
PC & $\mathbf{1 6 . 8} \%$ \\
Ernesto Talvi & $53.9 \%$ \\
Julio Ma. Sanguinetti & $32.8 \%$ \\
José Amorín Batlle & $13.3 \%$ \\
CA & $\mathbf{4 . 4 \%}$ \\
Guido Manini Ríos & $100 \%$ \\
\hline
\end{tabular}

Elaboración propia en base a datos de la Corte Electoral.

La sorpresa de estas elecciones fue la irrupción de CA que, en pocos meses de campaña y sin competencia interna, logró la mejor votación (4.4\%) que un partido pequeño obtuviera en este tipo de elecciones desde que se celebraron por primera vez en 1999. El resultado de la elección interna de CA llamó la atención y puso de manifiesto la potencia electoral de este nuevo partido y de su líder, Guido Manini Ríos. 


\section{Elecciones Nacionales}

Luis Lacalle Pou ganó la elección presidencial en la segunda vuelta realizada el 24 de noviembre de 2019. Esto supuso la alternancia en el gobierno luego de tres períodos consecutivos en que el FA ganó las elecciones con mayorías absolutas en el parlamento. Este resultado también determinó que a partir del primero de marzo de 2020 Uruguay volviera a tener un gobierno de coalición por primera vez en 18 años. ${ }^{22}$ En esta sección resaltamos los principales ejes de la campaña electoral, los resultados electorales y la composición del nuevo parlamento.

Las chances electorales del FA estuvieron en todo momento comprometidas. Tanto la evaluación del gobierno como las perspectivas que la ciudadanía veía en la economía hacían que la campaña electoral y la imagen del candidato fueran determinantes para revertir un escenario electoral adverso. Mientras que el FA obtuvo $47.8 \%$ en las elecciones de 2014, hacia el segundo trimestre de 2019, antes de conocerse el candidato, el FA recogía una intención de voto de aproximadamente el $34 \% .^{23}$ Las últimas estimaciones de intención de voto antes de las elecciones promediaron $41 \%$ para el FA. ${ }^{24}$

Daniel Martínez, el candidato del FA, fue intendente de Montevideo (la capital del país) hasta que renunció para dedicarse a la campaña presidencial. Los niveles de aprobación de su gestión lo hacían el candidato natural del FA. ${ }^{25}$ Sin embargo, a diferencia de José Mujica y Tabaré Vázquez (los candidatos presidenciales del FA en las tres elecciones anteriores), Martínez tenía el desafío adicional de construir su liderazgo interno en el FA. Bajo el lema de "vení con lo bueno, vamos a hacerlo mejor", tuvo que hacer frente a la mala evaluación de la gestión del gobierno y mostrar una propuesta que suponía algo nuevo respecto a los quince años de gobierno progresista. Los inicios de la campaña de Martínez hacia las elecciones nacionales de octubre fueron accidentados. Tuvo problemas inesperados para seleccionar a su compañera de fórmula. Aunque lo natural hubiera sido incorporar a Carolina Cosse, quien había sido segunda en la interna, decidió buscar una alternativa no planeada. Esta búsqueda se vio como un proceso improvisado y terminó con la nominación de Graciela Villar, una candidata con trayectoria política dentro del partido, pero sin visibilidad pública. ${ }^{26}$

22 La última coalición entre el PN y el PC se rompió en 2003 en medio de la crisis económica.

23 Promedio simple de estimaciones puntuales de encuestadoras de opinión pública, Banco de Datos, Facultad de Ciencias Sociales, UdelaR. Encuestadoras monitoreadas: Cifra, Equipos, Opción, Radar, Factum.

24 Ídem.

25 Al renunciar al gobierno departamental Martínez era evaluado positivamente por el $46 \%$ de los montevideanos y con un saldo a favor de 11 puntos. Subrayado. 2019, 21 de marzo. "Martínez terminó su gestión con $46 \%$ de aprobación y un saldo positivo de 11 puntos." Recuperado el 8 de abril de 2020 de https://www.subrayado.com.uy/martinez-termino-su-gestion-46-aprobacion-y-un-saldo-positivo-11puntos-n529397.

26 Graciela Villar fue sindicalista y se desempeñó desde los noventa como edil departamental de Montevideo (integrante del órgano legislativo de la Intendencia de Montevideo). 
El PN y su candidato Luis Lacalle Pou encararon la campaña bajo el lema "Es ahora." El desafío de Lacalle Pou fue consolidar su liderazgo entre los partidos opositores y mostrarse como un candidato que podía alcanzar la presidencia y desempeñarse como tal. La simultaneidad y vinculación de la primera vuelta presidencial y la elección parlamentaria hace que el porcentaje de votos que reciba el candidato presidencial también determine su contingente parlamentario. ${ }^{27} \mathrm{Al}$ iniciar el último mes de campaña previo a la primera vuelta, las encuestas de intención de voto mostraban que el candidato del PN sería quien seguramente pasaría a la segunda vuelta. Ante este escenario, el candidato del PN no esperó al resultado de octubre para tender los puentes con los restantes partidos del bloque opositor. En apariciones públicas recalcaba las coincidencias programáticas con los restantes partidos de la oposición (Montevideo Portal 2019). La noche de la elección, luego de conocido el resultado, los líderes de los partidos de la oposición (PC, CA, PI, y PG) indicaron su disposición a apoyar al candidato del PN en la segunda vuelta. Los pilares de la campaña del PN fueron la reactivación del crecimiento económico y el empleo, y la reducción de los niveles de delincuencia. Como forma de relanzar el crecimiento económico, el PN propuso la disminución del déficit fiscal en 900 millones de dólares (cerca de 2 puntos de PIB), y la rebaja de la carga fiscal y del precio de las tarifas públicas. Para mejorar los niveles de seguridad pública la propuesta de Lacalle Pou se centró en ofrecer mayores garantías al accionar policial y reestructurar la policía volviendo a poner como centro operativo a las comisarías. El candidato adelantó que, de ser electo presidente, buena parte de sus propuestas se procesarían a través de una Ley de Urgente Consideración que enviaría al parlamento apenas asumiera. Durante la campaña se hizo referencia a que la ley ya tenía varias centenas de artículos, pero su contenido no se hizo público hasta enero, durante el período de transición.

Ernesto Talvi, el candidato del PC, intentó disputarle a Luis Lacalle Pou el liderazgo de la oposición y llegar a la segunda vuelta frente al FA. La amplia victoria que logró en la elección primaria sobre Julio María Sanguinetti y el aumento de la participación en la primaria colorada respecto a 2014, generaron cierta expectativa sobre las posibilidades de Ernesto Talvi. Sin embargo, este efecto se diluyó rápidamente y sus niveles de intención de voto hacia octubre nunca llegaron a despegar. En agosto, el promedio de las estimaciones de intención de voto fue de $19 \%,{ }^{28}$ pero finalmente el PC obtuvo 12,3\% en la elección de octubre. Talvi trazó una estrategia destinada a captar votantes de centro, que se pudieran identificar con la tradición batllista, ${ }^{29}$ con el objetivo de captar

$27 \quad$ La primera vuelta de la elección presidencial y la elección de senadores y diputados no solo son simultáneas, sino que están vinculadas a nivel de partido. Esto supone que los electores no pueden votar a un candidato a presidente de un partido y a listas de senadores o diputados de otro partido.

28 Promedio simple de estimaciones puntuales de encuestadoras de opinión pública, Banco de Datos, Facultad de Ciencias Sociales, UdelaR. Encuestadoras monitoreadas: Cifra, Equipos, Opción, Radar, Factum.

29 El Batllismo representa el ala más de centro del Partido Colorado, toma su nombre de José Batlle y Ordoñez, presidente colorado en los períodos 1903-1907 y 1911-1915 que tuvo en sus dos gobiernos y a lo largo de su vida política un programa progresista en términos sociales y económicos. 
frenteamplistas desencantados y algunos votantes del PN con rechazo hacia la figura de Lacalle Pou (La Diaria 2019). Talvi también se resistió a habilitar una lista al Senado encabezada por Pedro Bordaberry, lo que para algunos analistas puede haber alienado a los votantes más conservadores del PC que en esta elección tuvieron otra oferta disponible como la de CA (Búsqueda 2019).

La elección no solo supuso un cambio de los partidos en el gobierno, sino también en el número de partidos relevantes y en sus contingentes legislativos. El FA bajó nueve puntos porcentuales respecto a la elección de 2014 (pasó del $47.8 \%$ al 39\%). Del total de votos que perdió el FA, el $68 \%$ fueron del interior del país. Por otro lado, el bloque de centro derecha se fragmentó y cinco partidos alcanzaron los votos necesarios para obtener representación parlamentaria en la Cámara de Diputados. Como lo muestra la tabla 2, el PN, el PC y el PI bajaron en su votación respecto a la elección de 2014. Entonces, la fuga de votos del FA no fue capitalizada por los partidos que hasta ahora fueron oposición en el parlamento. La votación de CA fue la principal novedad, obtuvo 11\%, solo 1.3 puntos porcentuales menos que el PC. En un sistema de partidos institucionalizado como el uruguayo, CA rompió con cierta estabilidad en la distribución de los votos del bloque de centro derecha y se constituyó en el partido nuevo más exitoso en su primera elección en las elecciones postdictadura.

Tabla 2. Resultados Elecciones Nacionales 2014 y 2019

\begin{tabular}{crrrrr}
\hline & \multicolumn{2}{c}{2014} & & \multicolumn{2}{c}{2019} \\
\cline { 2 - 3 } \cline { 5 - 6 } Partido & Primera vuelta & Segunda vuelta & & Primera vuelta & Segunda vuelta \\
\hline FA & $47.8 \%$ & $52.8 \%$ & $39 \%$ & $47.4 \%$ \\
PN & $30.9 \%$ & $40.5 \%$ & $28.6 \%$ & $48.9 \%$ \\
PC & $12.9 \%$ & & $12.3 \%$ & \\
PI & $3.1 \%$ & & $1 \%$ & \\
CA & - & & $11.0 \%$ & \\
PG & $1.1 \%$ & & $1.1 \%$ & \\
UP & $0.7 \%$ & & $0.8 \%$ & \\
PERI & & & & $1.4 \%$ & \\
\hline
\end{tabular}

Elaboración propia a partir de datos de la Corte Electoral

La fragmentación del sistema de partidos uruguayo trepó de un número efectivo de partidos en el Parlamento de 2.7 en la elección de 2014 hasta 3.5 como resultado de la elección de 2019. Como se observa en el gráfico 8, este es el valor más alto en la serie y es cercano a la fragmentación que mostró el sistema en las elecciones de 1989 y 1994. Estas dos elecciones son las últimas con mayoría simple para la elección presidencial y el aumento de la fragmentación obedece, en esas elecciones, al aumento de la votación del FA en detrimento de la votación de los partidos tradicionales. 


\section{Gráfico 8. Número Efectivo de Partidos Parlamentarios}

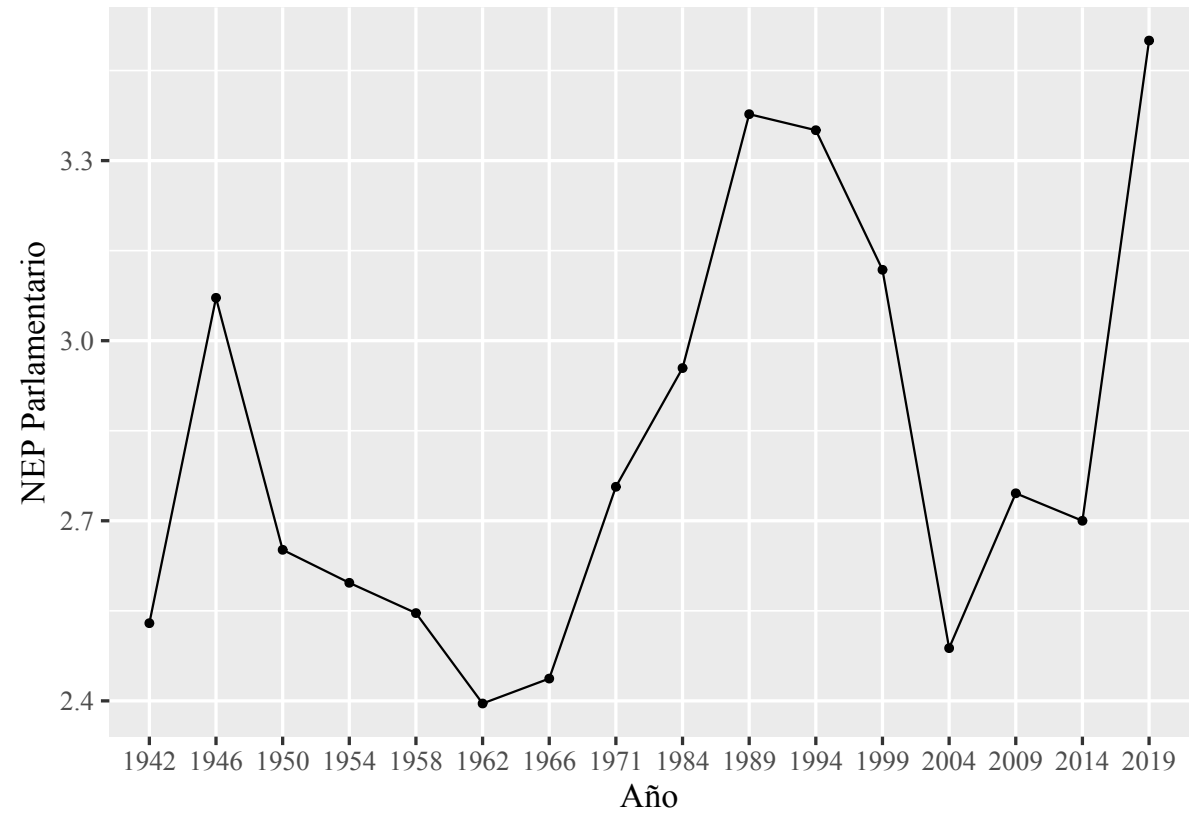

Fuente: Buquet y Piñeiro (2014). Datos actualizados.

La elección resultó en una redistribución del poder de las fracciones de los partidos. Tanto los partidos como sus fracciones son cruciales en la dinámica de formación de coaliciones de gobierno de Uruguay (Buquet, Chasquetti, y Moraes 1998; Altman 2000; Chasquetti, 2008). En el caso del FA, la elección de 2019 se caracterizó por la proliferación de nuevos sectores encabezados por líderes emergentes como el sector liderado por Mario Bergara (dos senadores y un diputado). El Partido Comunista y los sectores que apoyaron la precandidatura de Oscar Andrade, forjaron una alianza con la ex precandidata Carolina Cosse (dos senadores y siete diputados). El Movimiento de Participación Popular (MPP), fracción liderada por José Mujica, se mantuvo como la principal fracción del FA con veinticinco de los cuarenta y dos diputados del FA y cinco de los trece senadores (ver tabla 3).

Tabla 3. Composición de las Cámaras del Parlamento, por Partido y Fracción. Legislaturas 2015-2020, 2020-2025.

\begin{tabular}{lccccc}
\hline & \multicolumn{2}{c}{$2015-2020$} & & \multicolumn{2}{c}{$2020-2025$} \\
\cline { 2 - 3 } \cline { 6 - 7 } Partido/Fracción & Senadores & Diputados & & Senadores & Diputados \\
\hline FA & $\mathbf{1 5}$ & $\mathbf{5 0}$ & & $\mathbf{1 3}$ & $\mathbf{4 2}$ \\
MPP & 6 & 25 & & 5 & 25 \\
Compromiso Frenteamplista & 2 & 6 & & - & - \\
\hline
\end{tabular}




\begin{tabular}{|c|c|c|c|c|}
\hline \multirow[b]{2}{*}{ Partido/Fracción } & \multicolumn{2}{|c|}{$2015-2020$} & \multicolumn{2}{|c|}{$2020-2025$} \\
\hline & Senadores & Diputados & Senadores & Diputados \\
\hline PCU (más alianzas) & 1 & 1 & 2 & 7 \\
\hline FLS & 3 & 9 & - & - \\
\hline PS & 2 & 6 & 1 & 3 \\
\hline Casa Grande & 1 & 2 & 0 & 0 \\
\hline Vertiente Artiguista & 0 & 0 & 2 & 0 \\
\hline Liga Federal & 0 & 1 & 0 & 0 \\
\hline Asamblea Uruguay & - & - & 1 & 4 \\
\hline Nuevo Espacio & - & - & 0 & 1 \\
\hline Fuerza Renovadora & - & - & 2 & 1 \\
\hline PAR & - & - & 0 & 1 \\
\hline PN & 10 & 32 & 10 & 30 \\
\hline Todos (Lacalle Pou) & 6 & 16 & 7 & 20 \\
\hline Alianza Macional (Larrañaga) & 4 & 16 & 2 & 8 \\
\hline Todo por el Pueblo (Sartori) & - & - & 1 & 2 \\
\hline PC & 4 & 13 & 4 & 13 \\
\hline Vamos Uruguay (Bordaberry) & 3 & 11 & - & - \\
\hline Lista 15 (Amorín Batlle) & 1 & 2 & - & - \\
\hline Ciudadanos (Talvi) & - & - & 2 & 8 \\
\hline Batllistas (Sanguinetti) & - & - & 2 & 5 \\
\hline PI & 1 & 3 & 0 & 1 \\
\hline PERI & 0 & 0 & 0 & 1 \\
\hline CA & - & - & 3 & 11 \\
\hline UP & 0 & 1 & 0 & 0 \\
\hline PG & - & - & 0 & 1 \\
\hline
\end{tabular}

Elaboración propia en base a datos de la Corte Electoral.

En el PN, la incursión de Juan Sartori y la obtención de una banca en el Senado y dos en la Cámara de Diputados, quebró la dinámica de disputa tradicional entre dos fracciones dentro del PN. Por otro lado, la fracción Todos, liderada por Lacalle Pou obtuvo siete bancas en el Senado y veinte en la Cámara de Diputados, mientras que el sector liderado por Larrañaga dos bancas en el Senado y ocho en Diputados. En el PC, se recuperó la dinámica de competencia entre dos fracciones, perdida durante la hegemonía de la fracción Vamos Uruguay, liderada por Pedro Bordaberry y de las cuatro bancas de senadores, dos corresponden al sector de Talvi (llamado Ciudadanos) y dos a Batllistas Unidos (liderada por Sanguinetti y heredera del Foro Batllista); de las trece bancas de diputados del PC, ocho corresponden a la fracción de Talvi y cinco a la de Sanguinetti.

En este escenario de fragmentación, Daniel Martínez y Lacalle Pou pasaron a la segunda ronda para definir el futuro presidente. Lacalle Pou logró crear rápidamente una alianza electoral, conocida como Coalición Multicolor, integrada por 5 partidos que se definieron como opositores al gobierno del FA. Si bien durante la campaña de octubre, el PC y el PI habían marcado diferencias con CA y su líder Manini Ríos, esto no fue problema para formar una alianza electoral 
con un programa común una semana después de la primera vuelta (El País (El País 2019). El PC, PI, CA y el PG acompañaron la fórmula del PN y firmaron un acuerdo para formar un gobierno de coalición.

El resultado de la primera vuelta hacía prever una victoria clara de Luis Lacalle Pou sobre Daniel Martínez. Si nada ocurría en las tres semanas de campaña previas a la segunda vuelta, la única incertidumbre respecto al resultado estaba dada por los niveles de rechazo que el candidato de la oposición registraba en el electorado (49\% decían mostrar rechazo por Lacalle Pou) (Radio Uruguay 2019). Esto podía afectar su capacidad para concentrar los votos de la ciudadanía que, en la primera vuelta, habían optado por los otros partidos de la oposición. Sin embargo, cualquier duda pareció quedar disipada luego de que las encuestas de cara a la segunda vuelta mostraron desde un comienzo diferencias consistentes de más de 6 puntos entre Lacalle Pou y Martínez. ${ }^{30}$

En este escenario, la campaña hacia la segunda vuelta fue anodina, su ritmo solo se alteró por la realización del primer debate presidencial obligatorio, ${ }^{31}$ algunos reflejos de movilización territorial del FA y un video difundido por Manini Ríos (CA) al filo de la veda electoral en donde llamaba a los militares a votar por Lacalle Pou. El debate presidencial concitó interés, pero sus resultados no parecen haber cambiado mucho el panorama previo. Según muestran Bogliaccini et al (2019) las redes de retuits del debate se agruparon en dos polos y mostraron que los partidarios de los partidos de la coalición apoyaron consistentemente a Lacalle Pou. La campaña del FA mostró un cambio en la forma de trabajar con la estructura partidaria y sus adherentes. Esta campaña incorporó simpatizantes previamente no activados y puso su centro en la movilización de las bases del partido en el territorio. La iniciativa, llamada "Voto a Voto", se centró en el contacto personal para persuadir votantes. Por último, el hecho que tal vez suscitó un mayor impacto puntual fue el llamado del líder de CA a los integrantes del Ejército a que no se dejaran engañar por el FA y su campaña y votaran por Lacalle Pou.

A pesar de que el resultado sumado de los cinco partidos en la primera vuelta fue de $56 \%$ y que las encuestas de opinión previo a la segunda vuelta auguraban en promedio una diferencia de seis puntos a favor de Lacalle Pou, el candidato de la Coalición Multicolor solo logró imponerse por 1.5 puntos porcentuales. Lacalle Pou obtuvo el $48.9 \%$ de los sufragios emitidos mientras que Martínez recogió el 47.4\%. Los votos anulados y en blanco alcanzaron el 3.7\%.

30. El promedio de estimaciones en la intención de voto de Lacalle fue de $48 \%$ mientras que para Martínez ascendió a 42\% (Promedio simple de estimaciones puntuales de encuestadoras de opinión pública, Banco de Datos, Facultad de Ciencias Sociales, UdelaR. Encuestadoras monitoreadas: Cifra, Equipos, Opción, Radar, Factum.) La estimación más optimista para Martínez fue 43\% por las empresas Factum y Radar. Como contracara, el escenario más pesimista para Lacalle le otorgaba 47\% (Opción y Cifra, ambas en última medición)

31 Desde la campaña de 1994, no se realizaban debates entre candidatos presidenciales. En esta campaña se realizaron debates entre algunos de los precandidatos presidenciales de cara a las elecciones primarias y también un debate entre Lacalle Pou y Daniel Martínez antes de la primera vuelta. El debate previo a la segunda vuelta estaba estipulado por la Ley 19.827 promulgada en setiembre de 2019. 


\section{CONCLUSIONES}

El 2019 marcó la alternancia de partidos en el gobierno luego de quince años de administraciones del FA. El presidente electo Luis Lacalle Pou, a diferencia de lo que ocurrió con los presidentes del FA, no tiene mayorías absolutas de su partido en el parlamento. De hecho, el nuevo gobierno articulará una coalición de cinco partidos. A los dos socios tradicionales (PN y PC), se le suman dos partidos menores el PI y PG (dos diputados entre ambos) no necesarios para conformar mayorías, y CA que es imprescindible para lograrlas.

La reversión del resultado de la primera vuelta (Pérez-Liñán 2004), hizo que el contingente legislativo del partido del presidente sea el más bajo desde que funciona el sistema de elección presidencial por mayoría absoluta con doble vuelta. El PN cuenta con diez de los treinta senadores más la vicepresidenta y treinta de los noventa y nueve diputados. Asimismo, si bien la fracción del presidente es mayoritaria dentro de su partido, solo controla siete senadores y veinte diputados. Por otro lado, Lacalle Pou resultó electo presidente en segunda vuelta con menos votos que los que recibieron en primera vuelta la suma de los partidos que lo apoyaron (55\% en primera vuelta y $48.9 \%$ en segunda vuelta). El resultado de la segunda vuelta fue más ajustado de lo previsto. Esto cercenó a Lacalle Pou de gozar de un mandato político claro (Biglaiser 2016). La debilidad legislativa y la ausencia de mandato ponen en cuestión la capacidad del nuevo gobierno de impulsar reformas, en especial aquellas que no recogen apoyo popular o generan discrepancias al interior de la coalición (Pérez Bentancur, Piñeiro Rodríguez y Rosenblatt 2019).

Luis Lacalle Pou hizo campaña proponiendo reducir drásticamente el déficit fiscal sin aumentar impuestos $y$, al mismo tiempo, manteniendo las principales políticas sociales del FA. Las dificultades para cuadrar esta agenda están dadas por la contradicción entre los intereses de su base principal de apoyo electoral (sectores empresariales y agroexportadores) y los de los sectores populares. Los primeros esperan una reducción de la carga tributaria, la reducción de las tarifas de servicios públicos, y una mayor devaluación. ${ }^{32}$ Los segundos, son refractarios al recorte del gasto público social y a la reducción del poder de compra de los salarios y las jubilaciones. A las dificultades para poder llevar adelante esta agenda, se suma la estrategia de relanzar el crecimiento económico a través de la flexibilización de la negociación salarial y el enlentecimiento del crecimiento del salario real. Como señalan Pérez, Piñeiro y Rosenblatt (2019), es esperable que esta política genere resistencias en los sindicatos que han sido actores que se han fortalecido durante los gobiernos del FA.

Lacalle Pou anunció que buena parte de su agenda legislativa sería procesada a través de una Ley de Urgente Consideración de más de 400 artículos que sería

32 Esto quedó de manifiesto en las declaraciones de Carlos María Uriarte, ministro de Ganadería, Agricultura y Pesca, quien señaló que la devaluación era una "solución que no esperábamos, pero era lo que ansiábamos", en alusión al alineamiento con los intereses del sector agroexportador (La Diaria 2020b). 
presentada en las primeras semanas de su gobierno. Esta estrategia legislativa acorta los tiempos de discusión del parlamento y supone una aprobación tácita si no se vota en esos plazos establecidos. ${ }^{33}$ Sin embargo, cuando el proyecto estaba por ser enviado al parlamento se produjo el primer caso de COVID-19 y la pandemia modificó la agenda del gobierno que se concentró en cómo mitigar la propagación de la enfermedad.

\section{REFERENCIAS}

Aguiar, César. 2000. “La Historia y la historia: Opinión Pública y opinión pública en el Uruguay." Prisma 15: 7-45.

Altman, David. 2000. "The Politics of Coalition Formation and Survival in Multiparty Presidential Democracies." Party Politics 6(3): 259-83.

Altman, David. 2011. Direct democracy worldwide. New York: Cambridge University Press.

BCU. 2019. Informe Cuentas Nacionales. Año 2019. Montevideo: Banco Central del Uruguay

BID. 2018. ¿Cómo evitar el delito urbano?: el Programa de Alta Dedicación Operativa en la nueva Policía uruguaya. Montevideo: Ministerio del Interior.

Biglaiser, Glen. 2016. "Mandate and the Market: Policy Outcomes under the Left in Latin America." Comparative Politics 48(2): 185-204.

Bogliaccini, Juan A., Ignacio Borba, Cecilia Giambruno, Martín Opertti y Rafael Piñeiro Rodríguez. 2019. Twittarquía. La política de las redes en Uruguay. Montevideo: UCU- Ed. Túnel.

Bogliaccini, Juan A. y Rosario Queirolo. 2017. “Uruguay 2016: Mayorías parlamentarias en jaque y desafíos de revisión para sostener el modelo." Revista de Ciencia Politica 37(2): 589-612.

Buquet, Daniel. 2016. “La Transformación del Sistema de Partidos Uruguayo: Reglas Electorales, Adaptación y Equilibrio." En Los sistemas de partidos en América Latina 1978-2015. Tomo 2. Cono Sur y Países Andinos, editado por Flavia Freidenberg. Ciudad de México: UNAM-Instituto de Investigaciones Jurídicas- Instituto Nacional Electoral, 235-70.

Buquet, Daniel y Gustavo De Armas. 2004. "Claves de la evolución electoral de la izquierda: crecimiento demográfico y moderación ideológica." En La izquierda uruguaya entre la oposición y el gobierno, editado por Jorge Lanzaro. Montevideo: Fin de Siglo, 109-138.

Buquet, Daniel, Daniel Chasquetti y Juan Andrés Moraes. 1998. Fragmentación Política y Gobierno en Uruguay: ¿Un Enfermo Imaginario? Montevideo: Instituto de Ciencia Política - CSIC.

Buquet, Daniel, y Rafael Piñeiro. 2014. “La Consolidación de un Nuevo Sistema de Partidos en Uruguay." Debates 8(1): 127-48.

Buquet, Daniel y Rafael Piñeiro Rodríguez. 2015. "Factores de mediano y largo plazo para el análisis del proceso electoral de 2014 en Uruguay." En La campaña electoral 2014 en Uruguay: evolución del voto y del sistema de partidos, editado por Pablo Mieres. Montevideo: Fundación Konrad Adenauer- UCU, 17-34.

Búsqueda. 2019, 8 de julio. "Mensajes por WhatsApp y tensas reuniones mano a mano marcaron el alejamiento definitivo de Pedro Bordaberry de la política." Recuperado el 3

33 El artículo 168, numeral 7 de la Constitución uruguaya faculta al Poder Ejecutivo a enviar proyectos de ley con declaratoria de urgente consideración. Este mecanismo le impone plazos al Parlamento plazos para considerar el proyecto. En total, se otorgan 90 días para que el proyecto de ley pase por ambas Cámaras (45 días en primera Cámara, 30 en la segunda y 25 días más de haber modificaciones en segunda Cámara). Si ninguna cámara rechaza el proyecto por mayoría simple, o si la Asamblea de ambas cámaras no logra rechazarlo, el proyecto se transforma en ley. Se requieren 3/5 de los componentes de alguna de las Cámaras para suspender la urgencia del proyecto y tramitarlo ordinariamente. 
de marzo de 2020 de http:/ / busqueda.com.uy/nota/mensajes-por-whatsapp-y-tensas-reuniones-mano-mano-marcaron-el-alejamiento-definitivo-de-pedro.

Carneiro, Fabricio y Federico Traversa. 2018. "Uruguay 2017: Economic recovery and new political conflicts." Revista de Ciencia Politica 38(2): 379-407.

Chasquetti, Daniel. 2008. Democracia, presidencialismo y partidos políticos en América Latina. Evaluando la "difícil combinación." Montevideo: Universidad de la República, Ediciones Cauce - CSIC.

El Observador. 2019, 4 de agosto. "Manini Ríos: 'No estamos de acuerdo con la ideología de género que se quiere imponer'." Recuperado el 3 de marzo de 2020 de https:/ /www. elobservador.com.uy/nota/manini-rios-no-estamos-de-acuerdo-con-la-ideologiade-genero-que-se-quiere-imponer--20198416115.

El País. 2019, 5 de noviembre. "Este es el acuerdo firmado por los partidos de la coalición de cara al balotaje." Recuperado el 3 de marzo de 2020 de https:/ / www.elpais.com.uy / informacion/politica/acuerdo-partidos-coalicion-balotaje.html.

Erikson, Robert, Michael MacKuen y James Stimson. 2002. The Macro Polity. New York: Cambridge University Press.

Garcé, Adolfo y Jaime Yaffé. 2005. La Era Progresista. Montevideo: Fin de Siglo.

González, Luis Eduardo y Rosario Queirolo. 2000. "Las elecciones nacionales del 2004: Posibles escenarios." En Elecciones 1999-2000, editado por Oscar Bottinelli, Daniel Buquet, Gerardo Caetano, Agustín Canzani, Antonio Cardarello, Daniel Chasquetti, Gustavo de Armas, Adolfo Garcé, Luis Eduardo González, Aldo Guerrini, Jorge Lanzaro, Altaïr Magri, Constanza Moreira, Romeo Pérez Antón, Rosario Queirolo y Jaime Yaffé. Montevideo: Ediciones de la Banda Oriental, 299-321.

Hunter, Wendy y Timothy J. Power. 2019. "Bolsonaro and Brazil's Illiberal Backlash." Journal of Democracy 30(1): 68-82.

INE. 2020a. Boletín Técnico. Estimación de la pobreza por el método del ingreso 2019. Montevideo: Instituto Nacional de Estadística.

INE. 2020b. Boletín Técnico. Índice Medio de Salarios. Montevideo: Instituto Nacional de Estadística.

Kitschelt, Herbert, Kirk A. Hawkins, Guillermo Rosas y Elizabeth J Zechmeister. 2010. "Patterns of Programmatic Party Competition in Latin America." En Latin American Party Systems, editado por Herbert Kitschelt et al. New York: Cambridge University Press, $14-59$.

La Diaria. 2019, 5 de julio. “Ernesto Talvi: 'Las distancias que nos separan de Manini son oceánicas'." Recuperado el 3 de marzo de 2020 de https://ladiaria.com.uy/articulo/2019/7/ernesto-talvi-las-distancias-que-nos-separan-de-manini-son-oceanicas/.

La Diaria. 2020, 16 de enero. "Tren de UPM: se llegó a las firmas necesarias para intentar frenarlo." Recuperado el 19 de marzo deo 2020 de https://ladiaria.com.uy/articulo/2020/1/tren-de-upm-se-llego-a-las-firmas-necesarias-para-intentar-frenarlo/.

La Diaria. 2020b, 9 de marzo. "Uriarte sobre el aumento del dólar: 'Era lo que ansiábamos'." Recuperado el 13 de marzo de 2020 de https://ladiaria.com.uy/articulo/2020/3/ uriarte-sobre-el-aumento-del-dolar-era-lo-que-ansiabamos/.

Linz, Juan J. 1978. “The Breakdown of Democratic Regimes." Baltimore: The Johns Hopkins University Press.

López-Cariboni, Santiago. 2005. "Partidos desafiantes en América Latina: representación política y estrategias de competencia de las nuevas oposiciones." Revista de Ciencia Política 25(2): 37-64.

Luna, Juan Pablo. 2002. “¿Pesimismo estructural o voto económico? Sobre la racionalidad agregada del electorado uruguayo." Revista Uruguaya de Ciencia Política 13: 123-52.

Luna, Juan Pablo. 2014. Segmented Representation. Political Party Strategies in Unequal Democracies. Oxford: Oxford University Press.

Mainwaring, Scott (ed). 2018. Party Systems in Latin America. Institutionalization, Decay, and Collapse. New York: Cambridge University Press. 
Mainwaring, Scott y Timothy R. Scully (eds.). 1995. Building Democratic Institutions: Party systems in Latin America. Stanford: Stanford University Press.

Ministerio de Economía y Finanzas 2020, enero. "Reporte de Deuda Soberana." Recuperado el 25 de marzo de 2020 de http:/ / deuda.mef.gub.uy/innovaportal/file/28409/2/reporte-de-deuda-soberana-enero-2020.pdf.

Monestier, Felipe. 2007. "Movimientos sociales, partidos políticos y democracia directa desde abajo en Uruguay (1985-2004)." Informe final del concurso: Partidos, movimientos y alternativas políticas en América Latina y el Caribe. Programa Regional de Becas CLACSO.

Montevideo Portal. 2019, 3 de octubre. "Lacalle Pou: 'Abajo del programa nuestro hay cuatro programas de otros partidos'." Recuperado el 5 de marzo de 2020 de https:/ /www. montevideo.com.uy/Noticias/Lacalle-Pou--Abajo-del-programa-nuestro-hay-cuatro-programas-de-otros-partidos--uc731618.

Moreira, Constanza. 2004. Final de juego: del bipartidismo tradicional al triunfo de la izquierda en Uruguay. Montevideo: Trilce.

Norris, Pippa y Ronald Inglehart. 2019. Cultural Backlash: Trump, Brexit, and Authoritarian Populism. New York: Cambridge University Pres.

Pérez-Liñán, Aníbal. 2004. "La reversión del resultado y el problema de la gobernabilidad." En La elección presidencial mediante doble vuelta en Latinoamérica, editado por Rafael Martínez. Barcelona: Universitat Autònoma de Barcelona, 521-38.

Pérez Bentancur, Verónica, Rafael Piñeiro Rodríguez y Fernando Rosenblatt. 2019. “¿Qué hará la derecha uruguaya? Los enigmas de Lacalle Pou." Nueva Sociedad (Diciembre). Recuperado el 9 de junio de 2020 de https://www.nuso.org/articulo/que-hara-la-derecha-uruguaya/

Pérez Bentancur, Verónica, Rafael Piñeiro Rodríguez y Fernando Rosenblatt. 2020. How Party Activism Survives. Uruguay's Frente Amplio. New York: Cambridge University Press.

Pérez, Verónica y Rafael Piñeiro. 2016. “Uruguay 2015: Los desafíos de gobernar por izquierda cuando la economía se contrae." Revista de Ciencia Politica 36(1): 339-63.

Piñeiro Rodríguez, Rafael y Fernando Rosenblatt. 2020. "Stability and incorporation: Toward a new concept of party system institutionalization". Party Politics 26(2): 249-60.

Poder Ejecutivo. 2018. Reforma del Sistema de Previsión Social Militar. Mensaje y Proyecto de Ley. Montevideo.

Portal Factum. 2019, 5 de junio. "Los principales problemas del país." Recuperado el 28 de mayo de 2020 de https:/ / portal.factum.uy/analisis/2019/ana190605b.php

Queirolo, Rosario. 2020. "¿Qué significa el "giro a la derecha» uruguayo?" Nueva Sociedad. 287. Recuperado el 9 de Junio de 2020 de https://nuso.org/articulo/que-significa-el-giro-la-derecha-uruguayo/

Radio Uruguay. 2019, 5 de noviembre. “Equipos: Vázquez es el único político con saldo positivo de simpatía." Recuperado el 8 de abril de 2020 de https://radiouruguay.uy/ equipos-vazquez-es-el-unico-politico-con-saldo-positivo-de-simpatia/.

Rosenblatt, Fernando. 2018. Party vibrancy and Democracy in Latin America. Chile, Costa Rica and Uruguay. Oxford University Press.

Sartori, Giovanni. 1976. Parties and Party System. A Framework for Analysis. Cambridge: Cambridge University Press.

Townsend-Bell, Erica E. 2019. “Uruguay 2018: A Year of Mixed Signals and Open Questions.” Revista de Ciencia Politica 39(2): 367-90.

Yaffé, Jaime. 2005. Al centro y adentro: La renovación de la izquierda y el triunfo del Frente Amplio en Uruguay. Montevideo: Linardi y Risso.

Recibido: 10 de abril, 2020

Aceptado: 10 de junio, 2020 
Lihuen Nocetto es candidato a doctor en Ciencia Política por la Pontificia Universidad Católica de Chile, becario de Doctorado ANID y doctorante en el Instituto Milenio Fundamento de los Datos. Correo electrónico: lnocetto@uc.cl

Rafael Piñeiro es profesor asociado en el Departamento de Ciencias Sociales de la Universidad Católica del Uruguay. Sus trabajos han sido publicados en Comparative Political Studies, Party Politics, Latin American Politics and Society, Latin American Research Review, Journal of Democracy, Government Information Quarterly, Debates Política y Gobierno y Revista de Ciencia Política. Con Verónica Pérez Bentancur (Universidad de la República, Uruguay) y Fernando Rosenblatt (Universidad Diego Portales) publicó el libro How Party Activism Survives. Uruguay's Frente Amplio (Cambridge University Press, 2020). Correo electrónico: rafael.pineiro@ucu.edu.uy

Fernando Rosenblatt es profesor asociado en la Escuela de Ciencia Política en la Universidad Diego Portales e Investigador en el Instituto Milenio Fundamento de los Datos. Sus trabajos han sido publicados en Comparative Political Studies, Party Politics, Latin American Politics and Society, Latin American Research Review, Democratization, Política y Gobierno y Revista de Ciencia Política. Su libro Party Vibrancy \& Democracy in Latin America fue publicado por Oxford University Press en 2018. Con Verónica Pérez Bentancur (Universidad de la República, Uruguay) y Rafael Piñeiro Rodríguez (Universidad Católica del Uruguay) publicó el libro How Party Activism Survives. Uruguay's Frente Amplio (Cambridge University Press, 2020). Correo electrónico: fernando.rosenblatt@mail.udp.cl 